\title{
Mecanismos de coordenação em redes de pequenos negócios supermercadistas no estado de São Paulo: formalidade, informalidade e coesão relacional
}

\author{
Coordination mechanisms in network of supermarket small \\ business in the state of Sao Paulo: formality, informality \\ and cohesion relationship
}

\author{
Luciano Mitidieri Bento Garcia' \\ Luiz Fernando de Oriani Paulillo'
}

\begin{abstract}
Resumo: Alguns supermercadistas de pequeno porte têm procurado enfrentar o maior poder de mercado dos grandes grupos do setor mediante ações cooperativas que se desenvolvem nas chamadas centrais de negócio. De acordo com as perspectivas teóricas representadas pelo neoinstitucionalismo e pela abordagem de redes, especialmente quanto à sua perspectiva relacional, as centrais de negócio de pequenos supermercadistas podem ser definidas como redes cooperativas horizontais, cuja eficácia está associada aos mecanismos formais e informais de coordenação e à coesão relacional entre seus membros. O objetivo deste trabalho foi analisar a percepção de eficácia, os mecanismos de coordenação e a coesão relacional de uma central de negócios, dentro de uma perspectiva dinâmica, antes e após a fusão ocorrida com uma central de maior porte. Dentro de uma abordagem qualitativa de pesquisa e, para aferir as percepções dos entrevistados com relação à eficácia da rede estudada, a efetividade de seus mecanismos formais e informais de coordenação e a intensidade das relações para a coesão, este trabalho está baseado em entrevistas semiestruturadas com os integrantes da referida central, utilizando-se de um roteiro composto por itens relacionados à percepção de eficácia, aspectos de coordenação e coesão relacional. Constatou-se uma alta percepção de eficácia entre os supermercadistas da rede estudada e que aumenta consideravelmente a partir da integração com a rede de maior porte. Constatou-se também uma importante convivência entre mecanismos formais e informais de coordenação, além de relações coesas entre os membros da central.
\end{abstract}

Palavras-chave: Central de Negócios. Redes. Coordenação. Coesão. Eficácia.

\begin{abstract}
Some small supermarkets have sought to address the increased market power of large groups of the sector through cooperative actions that develop in networks called central business. This work presents and analyzes one of these central business districts in the state of S. Paulo that operates through networks of relationships. Another important contribution is to show the dynamics embedded in this central business district after a merger with a broader network, in a larger municipality. According to the theoretical perspectives represented by the new institutionalism and network approach, especially relational governance, the central business district of small supermarkets can be defined as horizontal cooperative governance actors, where the efficiencies of the goals are linked to formal and informal mechanisms of coordination and strength of relational cohesion that emerged among its members. According to a qualitative research approach and in order to gauge respondents' perceptions regarding the effectiveness of the network studied, the effectiveness of their formal and informal mechanisms of coordination and intensity of relations for cohesion, the work is based on semi-structured interviews with members of the network using a script composed of items related to perceived effectiveness, aspects of coordination and relational cohesion. There is a high perception of effectiveness among the members of the network studied, and it has increased considerably from the integration with the larger network. There is also an important interaction between formal and informal mechanisms of coordination and maintenance of a cohesive relationship among members.
\end{abstract}

Keywords: Central Business District. Networks. Coordination. Cohesion. Effectiveness.

\footnotetext{
${ }^{1}$ Departamento de Engenharia de Produção - DEP, Universidade Federal de São Carlos - UFSCar, Rod Washington Luís, Km 235, CEP 13565-905, São Carlos, SP, Brasil, e-mail: 1garcia@dep.ufscar.br; dlfp@ power.ufscar.br
} 


\section{Introdução}

No Brasil, o setor supermercadista se caracteriza, de um lado, pela existência de um grande número de pequenos estabelecimentos localizados normalmente em bairros e periferias das cidades e, de outro lado, pela atuação de grandes cadeias supermercadistas, que possuem uma série de vantagens sobre os pequenos supermercados independentes. Uma destas vantagens é o maior poder de barganha junto aos fornecedores, devido, entre outras razões, ao maior volume de compras, o que, segundo Esteves (2009), tem gerado uma crescente concentração de mercado. Para os supermercados de menor porte, uma forma de se contrapor a esta vantagem tem sido a união em redes ou formas de coordenações horizontais, denominadas centrais de compras ou centrais de negócio. De acordo com Soares et al. (2011), ao se unir sob a forma de redes, os pequenos supermercadistas se apropriam de uma série de benefícios competitivos, não apenas no que tange à sua gestão operacional e organizacional, como também na geração de capital social e aprendizado por meio das relações pessoais e trabalho conjunto que passam a existir entre seus membros. As centrais de negócios formam uma rede interorganizacional de atores independentes em um empreendimento conjunto. Tal como coloca Provan, Fish e Sydow (2007), o conceito de rede interorganizacional adotado neste trabalho é amplo, com várias abordagens teóricas, mas, segundo estes autores, com alguns elementos comuns, tais como: interação social, relações, ligações, colaboração, ação conjunta, confiança e cooperação. Com relação à cooperação, esta impõe a necessidade de mecanismos de coordenação que, de acordo com Powell (1990) e Powell e Smith-Doerr (1994), possuem dimensões formal e informal. O bom funcionamento destes mecanismos, bem como sua contribuição para a eficácia da cooperação, depende, especialmente quanto à sua dimensão informal, de relações coesas entre seus participantes. A dimensão de coesão relacional utilizada neste trabalho é social e trabalhada por vários autores, entre os quais Holmlund e Tornroos (1997), que consideram a intensidade das relações em termos de comprometimento, confiança, clima, atratividade e vínculos sociais.

Tendo em vista o interior do Estado de S. Paulo, a questão de pesquisa que se colocou neste trabalho foi, em face do fenômeno do surgimento nos últimos anos de várias centrais de pequenos supermercadistas, analisar a percepção de eficácia de seus membros, as características dos seus mecanismos formais e informais de coordenação e o papel da coesão relacional na ação cooperativa, bem como a evolução dos indicadores de coordenação e coesão dentro de uma perspectiva dinâmica representada pelo ingresso dos supermercadistas na rede e posterior incorporação a uma rede maior. Para isso, procedeu-se a identificação e análise das percepções dos membros da rede estudada quanto à eficácia da rede em termos financeiros e não financeiros, quanto à força dos mecanismos de coordenação e quanto à intensidade das relações entre seus membros (coesão relacional da rede).

Considerando o caráter social das variáveis e condições escolhidas para a análise e a dinâmica sofrida pelo objeto de estudo, a abordagem metodológica adotada neste trabalho foi a pesquisa qualitativa. Segundo Neves (1996), numa visão diversa da abordagem quantitativa, a pesquisa qualitativa normalmente não usa instrumental estatístico para analisar os dados (o que não significa que instrumentos quantitativos sejam totalmente descartados), mas sim uma perspectiva descritiva em sua essência, feita pela interação direta do pesquisador com seu foco de estudo. O pesquisador que lança mão desta abordagem tem por objetivo principal compreender um determinado fenômeno e posteriormente interpretá-lo, a partir da visão do agente participante da pesquisa.

O objeto de estudo deste trabalho se localiza em uma central de negócios de pequenos estabelecimentos supermercadistas do interior do Estado de S. Paulo (doravante denominada rede Orion) e que, neste trabalho, foi analisada como uma rede cooperativa horizontal com relações econômicas e sociais interorganizacionais. Constituída no início por doze integrantes, a rede Orion sofreu, ao longo do tempo, uma redução para o número de sete supermercadistas (no final de 2010).

Foram feitas entrevistas com os membros da rede Orion que buscaram qualificar as intensidades das relações (coesão relacional) e a força dos seus mecanismos formais e informais de coordenação. Neste caso, considerou-se a mudança experimentada pelos pequenos supermercadistas com a fusão, por meio de relatos colhidos antes (final de 2009) e depois da fusão (início de 2010). O trabalho mostra os impactos desta absorção, em termos de coordenação e coesão, para os associados da rede. Este artigo estrutura-se em seis itens, sendo o item 1 representado por esta introdução.O item dois apresenta uma breve revisão da abordagem neoinstitucional de redes. O item três apresenta um panorama recente do setor supermercadista no Brasil para mostrar o contexto em que se insere uma forma organizacional alternativa ao grande negócio que emergiu e é bem sucedida, mesmo diante da crescente concentração promovida por grupos varejistas nacionais e internacionais. No item quatro, são apresentadas as centrais de negócios e suas características. As considerações metodológicas são apresentadas no item cinco, em que também são colocadas as variáveis relacionais sobre os mecanismos de coordenação utilizados para a análise da central supermercadista enfocada. A análise dinâmica de cada variável é apresentada no item 6 , envolvendo a percepção de eficácia de cada rede, os mecanismos 
de coordenação e a coesão relacional. No item 7, são apresentadas as conclusões finais.

\section{Perspectiva de redes - aspectos teóricos}

O conceito típico da Nova Economia Institucional e da Economia dos Custos de Transação (NEI/ECT), relacionado com as principais opções de governança polarizadas principalmente entre o mercado e a hierarquia, poderia levar em consideração também formas de organização em rede, como alternativa de governança. Uma abordagem que complementa esta questão se encontra no trabalho de Menard (2004) - que trata de estruturas híbridas em acordos com ajustes mútuos e compartilhamentos variados - oferece possibilidades de aplicação para redes de cooperação nas quais se constituem as centrais de negócios de pequenos supermercadistas no Estado de São Paulo. Em termos de governança, são registradas pelo autor algumas regularidades empíricas de estruturas híbridas, tais como: associação/cooperação, contratos e competição, sendo que as centrais de negócios poderiam ser incluídas no primeiro caso.

Em todas estas modalidades de arranjos híbridos, e de acordo com Menard (2004), um dos principais desafios parece ser conciliar autonomia e interdependência. Na verdade, cada membro da rede investe de alguma forma na criação de dependência mútua, mas existe também a necessidade de manutenções dos direitos de propriedade e da autonomia nas decisões. Assim, a interdependência se dá por meio de duas estratégias básicas: os desenvolvimentos de complementaridades e compartilhamentos. Porém, a interdependência cria uma situação típica de especificidade da negociação, cujo oportunismo potencial deve ser controlado por contratos que explicitem as possibilidades de sanção, de esquemas de monitoramento e de processos criteriosos de seleção de parceiros e resolução de conflitos.

A centralização, a formalização da coordenação e o monitoramento em rede teriam, segundo Menard (2004), uma relação direta com a magnitude da interdependência desenvolvida entre seus membros. Assim, quanto maior a interdependência (provocada por maior especificidade do negócio e maior incerteza), maiores as necessidades de centralização e formalização com o estabelecimento de salvaguardas, seleção rigorosa de parceiros e regras de enforcement (fazer cumprir) sobre os membros. Os riscos contratuais do oportunismo, a falta de coordenação (incerteza) e a indefinição quanto à proteção/distribuição de ganhos, além de condicionados pela interdependência (especificidade), podem também ser gerados por situações ligadas a problemas de mensuração, mudanças ambientais, falhas no ambiente institucional e a direitos de propriedade mal definidos. Todos estes fatores vão se relacionar com a forma de governança de uma forma híbrida.

Quanto à seleção de parceiros, Menard (2004), esta relaciona três critérios básicos observados em suas pesquisas: experiência passada, arranjos híbridos prévios e reputação. Este último constatou-se ter sido um critério fundamental na rede de cooperação estudada.

Por fim, Menard (2004) faz alusão também a incentivos extracontratuais para a consolidação da cooperação em formas híbridas, tais como a definição do número de parceiros, a duração do relacionamento (maior tempo de relacionamento, maior a cooperação), especificidades contratuais em termos de qualidade e quantidade, salvaguardas complementares formais (garantias financeiras) e informais (relacionamento e reputação), sendo que a confiança é considerada uma maneira de assegurar os funcionamentos das transações quando os contratos são incompletos.

Por sua vez, Powell (1990) aponta que, considerando as três formas básicas de organização - mercado, redes e hierarquia - e no que concerne às redes, estas três formas podem coexistir em alguns arranjos organizacionais. Este autor apresenta algumas críticas ao modelo trilateral (mercado, contrato e hierarquia) apresentado pela nova economia institucional, questionando, por exemplo, o caráter atemporal da noção de mercado dada por este modelo quando se sabe que o sistema de mercado é historicamente determinado. Este autor considera também que a firma hierarquizada, com fronteiras definidas, se constitui apenas em uma opção ao lado de outras tais como os cartéis, os negócios familiares e as extensas empresas comerciais sem fronteiras definidas.

Evidências empíricas desta posição, tais como o vale do silício nos EUA e os arranjos cooperativos no norte da Itália dão conta das existências de empresas de pequeno e médio porte com um padrão de crescimento direcionado por externalidades positivas advindas de redes de relações muitas vezes preexistentes. Este processo confere a estas firmas condições competitivas em termos de obtenção de recursos e atendimento de necessidades funcionais.

Partindo do pressuposto de que as trocas econômicas estão enraizadas em um contexto socialmente estruturado, Powell (1990) apresenta uma forma especial de coordenação da atividade econômica caracterizada pela sua dependência de relacionamentos, reputação e interesses mútuos, constituída por ações de cooperação baseadas em reciprocidade e confiança. Não se constitui esta forma cooperativa uma estrutura de governança de mercado, nem uma estrutura hierárquica, e nem mesmo híbrida, mas sim uma rede colaborativa de empresas que difere destas estruturas quanto ao tipo e padrão de 
interação entre os agentes econômicos, e que possui as seguintes características: a) especificações dos itens trocados dificilmente mensuráveis; b) relações cujo prazo de duração e a recorrência tornam difícil a separação entre as partes; c) relações de obrigação e reputação que criam interdependências sem perda de autonomia.

Powell (1990) também afirma que a questão da reciprocidade é central para as redes existirem e funcionarem. São várias as visões sobre este conceito. Algumas, mais sintonizadas com o conceito de autointeresse individual, entendem a reciprocidade no sentido de equivalência e cálculo estratégico, na equivalência de benefícios e na equivalência de retribuições. Já nas interpretações sociológicas, a reciprocidade é colocada dentro de uma perspectiva de longo prazo. As necessidades de segurança e de estabilidade encorajam as buscas de novas execuções de tarefas, promoções de aprendizado e trocas de informações. Surgem, então, as cooperações entre os agentes, que emergem destes interesses coletivos e mútuos e não individuais. É gerada assim a confiança que reduz as complexidades e as incertezas das transações (neste sentido, a confiança pode ser encarada como redutora de custos de transação), lubrificando-as de modo mais efetivo do que a previsão proporcionada pelo mercado, a autoridade dada pela hierarquia, a barganha ou os contratos de longo prazo relacionados às formas híbridas.

De acordo com Sacomano Neto e Truzzi (2005), a perspectiva de redes pode ser dividida em duas vertentes: análise de redes e governança de redes. A governança de redes se volta para os aspectos relacionados com a formação e organização das redes, com o acesso a recursos redutores de dependência, melhora na posição competitiva e nos laços organizacionais, na formulação de estratégias para as incertezas e na exploração de inovações e novos mercados. Na governança em redes, as palavraschave são: coordenação, cooperação, restrições e oportunidades. Nesta perspectiva, existe a preocupação em se estudar a forma de se governar as relações entre os atores. No caso de formas de cooperação, há a necessidade de se estudar a coordenação entre os atores.

Os mecanismos de coordenação dos participantes das redes que se mantêm independentes são aspectos importantes da governança em redes. Estes mecanismos podem ser formais (contratos e estatutos, regulamentos) ou informais (normalmente baseados em confiança, reputação, reciprocidade). Sacomano Neto e Truzzi (2005) citam Grandori e Soda (1995) para expor os principais mecanismos de coordenação. Entre estes, os mais pertinentes para o objeto deste trabalho são: monitoramento e controle social sobre os participantes da rede (com aspectos formais e informais), sistemas de seleção de parceiros e suporte público ou externo.
E para a análise de redes (que possui três níveis: posicional - que trabalha, por exemplo, com o conceito de centralidade dos atores da rede; estrutural - que lida, entre outros, com o conceito de densidade de redes; e relacional - que tem sua atenção aplicada à intensidade das relações entre os membros de uma rede) este trabalho incorpora elementos da análise relacional de redes.

$\mathrm{Na}$ análise relacional, o importante é medir/ aferir a intensidade de relacionamento entre pares (forte ou fraca). Relações fortes geram conformidade e homogeneidade de comportamento e formação de normas, entendidas como expectativas de comportamento, resultando, por sua vez, em coesão relacional. Conforme Sacomano Neto e Truzzi (2005), para aferir a intensidade e a extensão das relações em uma rede, o nível de cooperação e o comprometimento de seus membros (e, portanto, o nível de coesão relacional), tem-se alguns atributos relacionais importantes tais como: vínculos anteriores, intensidade emocional, reciprocidade, frequência de interação, velocidade de resolução de problemas, existência da formalidade/informalidade na relação e mecanismos de resolução de problemas.

Os mecanismos de coordenação e os atributos relacionais, tal como apresentados neste item, são as duas dimensões que foram utilizadas para caracterizar a rede estudada, bem como a percepção de eficácia de seus membros, que possui uma relação com a coordenação e a coesão relacional. De acordo com Farina et al. (1997) e Balestrin e Vargas (2003), citados no trabalho de Behncker Jerônimo, Fensterseifer e Nunes da Silva (2005), o conceito de eficácia, entendido neste artigo como a coerência entre objetivos inicialmente traçados e resultados esperados, é mais amplo que o conceito de eficiência, comumente definido como uma relação entre insumos e benefícios. Considera-se, portanto, resultados econômico-financeiros (aumento de faturamento e lucro, diminuição de custos, etc.) e resultados não financeiros (poder de barganha, aprendizado, troca de experiências, melhor tomada de decisão, etc.).

\section{Supermercados - panorama geral recente}

Segundo dados da ABRAS (Associação Brasileira de Supermercados), o processo de concentração de mercado no setor supermercadista cresceu porque os cinco maiores grupos passaram a ocupar aproximadamente $27 \%$ do faturamento total do setor em 1997 para quase $40 \%$ em 2002, sendo que entre 2002 e 2005 esse domínio de $40 \%$ avançou também para o número de lojas (MADUREIRA, 2007). A Tabela 1 mostra a liderança dos principais grupos supermercadistas no Brasil em número de estabelecimentos entre 2006 e 2009. 
Tabela 1. Evolução da Concentração de Mercado do Setor Supermercadista.

\begin{tabular}{ccccc}
\hline Amostra/Ano & $\mathbf{2 0 0 6}(\boldsymbol{\%})$ & $\mathbf{2 0 0 7}(\boldsymbol{\%})$ & $\mathbf{2 0 0 8}(\boldsymbol{\%})$ & $\mathbf{2 0 0 9}(\boldsymbol{\%})$ \\
\hline 5 maiores & 36 & 39 & 41 & 43 \\
10 maiores & 41 & 47 & 46 & 48 \\
50 maiores & 53 & 58 & 58 & 60 \\
\hline
\end{tabular}

Fonte: ABRAS (ASSOCIAÇÃO..., 2010a)

De qualquer modo, em que pese a concentração crescente no Brasil, observa-se que, em outros países como EUA e França, estes níveis eram em 2006 de 50\% e $63 \%$, respectivamente (os cinco maiores grupos para os EUA e no caso da França, os quatro maiores grupos), e no Reino Unido, os quatro maiores grupos concentravam $90 \%$ do faturamento de varejo alimentar, o que denota a manutenção de algum grau de pulverização e concorrência no mercado brasileiro, a despeito da tendência mundial na direção da concentração do setor supermercadista. (LUKIANOCENKO, 2007).

Dentre as razões para o relativo aumento da concentração a partir de 2007, Hilário (2008) destaca o aumento da renda dos trabalhadores no Brasil. Porém, o antigo atrativo dos pequenos supermercados, representado pela conveniência do hábito, da proximidade física e do mix mais específico de produtos não foi totalmente eliminado, mas perdeu um pouco do seu apelo em favor da maior variedade encontrada em lojas com área de vendas superior a $250 \mathrm{~m}^{2}$, especialmente aqueles dentro da faixa de 800 a 2.000 metros quadrados.

Hilário (2008) observa que, além do maior sortimento, os estabelecimentos maiores também passam a oferecer mais espaço de trânsito interno e mais eficiência nas operações. Além disso, para reforçar esta tendência, Hilário (2008) destaca o ocorrido com dois formatos importantes no setor supermercadista, as lojas com mais de $4.000 \mathrm{~m}^{2} \mathrm{e}$ com $500 \mathrm{~m}^{2}$. As primeiras, com as características operacionais dos hipermercados, oferecem, além de uma grande variedade de produtos, uma área de não alimentos, como oferta de aparelhos eletroeletrônicos, por exemplo, cujo preço competitivo representa um apelo adicional. No segundo formato, característico de lojas de desconto com itens básicos a preços baixos, como o Dia \% do grupo Carrefour, o quesito eficiência emerge como fator principal e a sua expansão parece repetir uma tendência já existente em diversos países da Europa.

\section{As centrais de negócios}

De modo amplo, as centrais de negócios podem se enquadrar no conceito de redes de cooperação horizontal. Numa definição mais específica, as centrais de negócios são associações entre pequenos estabelecimentos para obtenção de melhores condições de barganha, formando um padrão homogêneo de atendimento, preços e layout de loja, num processo semelhante a outros setores como farmácias, papelarias, lojas de material de construção (MOLDERO, 1998).

O modelo de centrais de compras não pode ser considerado uma inovação nacional. Wilder (2003) afirma que, nos EUA, a partir dos anos 1920, nasce uma associação de supermercados independentes, International Grocers Alliance - IGA, justamente com o objetivo de melhorar as condições competitivas e enfrentar os grandes grupos em melhores condições. Além de maior poder de barganha junto a fornecedores, uma meta importante da IGA seria proporcionar, aos seus participantes, padronização de procedimentos e, consequentemente, maior eficiência das operações.

$\mathrm{Na}$ Europa, esta forma de arranjo, existente desde os anos 1920, empregava em 2002 mais de 2 milhões de pessoas e faturava cerca de 400 milhões de euros em mais de 420 mil pontos de venda. Wilder (2003) define as relações de uma rede de compras como "simbióticas" na medida em que é gerado um valor para todos os participantes sob a forma da redução no número de transações, reduzindo, portanto, os custos de transação. Cria-se assim uma estrutura híbrida de governança que combina hierarquia e mercado, na medida em que as firmas participantes permanecem independentes, mas combinam algumas atividades como compras auferindo com isso economias de escala.

De acordo com Saab e Gimenez (2000), no Brasil e diante do movimento de concentração que vem ocorrendo nos últimos anos entre os grandes grupos supermercadistas, os pequenos supermercados se viram compelidos a agir, sob pena de serem eliminados do mercado. Os grandes grupos, de acordo com Martinelli, Ghisi e Camargo (2002), possuem, entre outras vantagens, expressiva participação de mercado, preços competitivos e poder de barganha junto aos fornecedores impondo-lhes, preços, descontos e exigindo também bonificações e melhores condições de pagamento.

Além deste poder de mercado dos grandes grupos, outro desafio para os pequenos supermercados se constitui num movimento estratégico mais recente dos grandes grupos na direção de aquisições de cadeias regionais. Além disso, grandes cadeias estariam implantando modelos de lojas de menor metragem com estrutura semelhante aos supermercados de 
bairro, visando um consumidor mais propenso a fazer compras diárias.

Sobre as características gerais dos participantes das centrais, Martinelli, Ghisi e Camargo (2002) os define, majoritariamente, como pequenos supermercados localizados normalmente em bairros mais distantes, com área entre 350 e $700 \mathrm{~m}^{2}$. Operando com ênfase em autosserviço. Possuem um número médio de até sete caixas (check-outs) e um mínimo de dois caixas. São firmas que comercializam, de forma predominante, alimentos de mercearia, carnes, frios, laticínios e hortifrutigranjeiros, higiene e limpeza, e que têm por característica o alto giro e baixas margens. Totalizam em média de 600 a 1.200 itens de produtos, auferindo um faturamento médio em torno de R $\$ 100.000,00 /$ mês. Este formato de varejo, segundo relatado em Saab e Gimenez (2000), representava em 2000 aproximadamente $60 \%$ do total de estabelecimentos no Brasil.

Wilder (2003) aponta algumas vantagens da operação por centrais, tais como: a) troca de experiências; b) ampliação do mix de produtos; e c) crescimento de vendas para os participantes das centrais. Em termos operacionais, Saab e Gimenez (2000) observam que ocorre uma vantagem para as centrais em comparação com os negócios que permanecem independentes e que é resultante da padronização das operações. Consequentemente, tem-se a criação de uma identidade com o consumidor em termos de layout de loja, uniforme de funcionários, embalagens de compras, promoções e cartazes. Outras vantagens mais subjetivas estariam ligadas à troca de experiências e informações entre os integrantes das redes com melhoria na gestão e redução de desperdícios. Em suma, a redução de custos dos pequenos supermercadistas, propiciada pela união cooperativa, juntamente com outros benefícios, lhes tem dado melhor condição competitiva, a ponto de já estar chamando a atenção dos grandes grupos.

A melhor possibilidade de sobrevivência de pequenos estabelecimentos supermercadistas, proporcionada pela atuação por meio de centrais de negócio, tem gerado um crescimento desta modalidade de atuação. Especificamente com relação ao Estado de S. Paulo, que concentra mais de $30 \%$ do mercado supermercadista brasileiro, pode-se constatar este fato pelos números exibidos na Tabela 2 a seguir, na qual se vê uma evolução física das centrais de negócios entre os anos de 2008 e 2009, tanto em termos de números de check-outs, como em área de vendas e número de funcionários.

Por fim, as centrais de negócios são redes pautadas em ações de associativismo e cooperação, como uma ação dos pequenos supermercados ante a expansão das grandes cadeias e a concentração do mercado. As centrais tentam suprir as deficiências de escala e de poder de barganha típicas do pequeno varejo mediante ação conjunta de compras junto aos fornecedores, sem que se percam as vantagens típicas dos pequenos estabelecimentos de vizinhança, representadas por maior conhecimento dos clientes, devido a maior proximidade espacial, maior frequência de compras e um relacionamento mais íntimo com o consumidor. A compra conjunta dá ao grupo melhores possibilidades de negociação em termos de preço e prazo, o que pode ser repassado pelos pequenos supermercadistas aos seus preços finais, gerando, consequentemente, condições competitivas diante das grandes cadeias. Segundo Saab e Gimenez (2000), o próprio acesso a determinados fornecedores, que seria impossível para o pequeno supermercado individual, passa a ser possível a partir da cooperação entre eles.

\section{Metodologia}

Esta pesquisa foi delineada a partir do estudo de caso de uma central de negócios no município de São Carlos (SP) e que, posteriormente, foi fundida com uma central de Ribeirão Preto (SP). Segundo Yin (2001), o estudo de caso é apropriado para situações em que a forma de pergunta é "como" e/ou "porque", e não se tem inteiro controle sobre as variáveis. No estudo de caso, o foco está em acontecimentos contemporâneos, portanto, não há controle por parte do pesquisador, razão pela qual seu caráter, no caso deste estudo, é eminentemente qualitativo (YIN, 2001).

Assim sendo, em sua essência, este trabalho pode ser considerado qualitativo, de natureza exploratória e descritiva, realizado por meio de estudo de caso. Os dados foram coletados por meio de entrevistas semiestruturadas gravadas junto aos participantes da central de negócio, seguindo um roteiro composto por itens relacionados à percepção de eficácia, efetividade da coordenação e coesão relacional. $\mathrm{O}$ referido anexo encontra-se anexo ao final deste artigo. Complementou-se o estudo com a análise de conteúdo dos relatos colhidos.

Tabela 2. Evolução física das centrais de negócio.

\begin{tabular}{ccc}
\hline Indicadores físicos & $\mathbf{2 0 0 8}$ & $\mathbf{2 0 0 9}$ \\
\hline Check-out & 1.937 & 2.074 \\
Funcionários & 12.171 & 13.037 \\
Metro quadrado & 215.737 & 229.217 \\
\hline
\end{tabular}

Fonte: ABRAS (ASSOCIAÇÃO..., 2010b) 
Visou-se, com as entrevistas, levantar os mecanismos formais e informais de coordenação existentes, as características das relações, bem como a sua força, na percepção de seus membros, para a institucionalização da cooperação. Voltou-se inicialmente para a percepção de eficácia para cada membro e para o grupo. A eficácia evidenciada na pesquisa está relacionada com a competitividade de cada supermercadista e o que estes esperavam a partir de sua participação em rede. Posteriormente, a pesquisa tratou de questões relacionadas com os mecanismos horizontais de coordenação (formais e informais). Estes mecanismos possuem um importante papel para a construção da cooperação nas redes estudadas e para a sua eficácia. Procurou-se aferir a dimensão da contribuição destes mecanismos, por sua caracterização no questionário e da percepção de sua força nas visões dos entrevistados. Os chamados mecanismos de coordenação têm sua fonte teórica localizada na perspectiva da governança de redes. Os mecanismos de coordenação utilizados neste trabalho foram inspirados na classificação preconizada em Grandori e Soda (1995) e são os seguintes:

- Coordenação social e controle sobre os parceiros: relacionado às normas enquanto expectativas de comportamento participativo, atitude cooperativa, ética, voltado para o bem comum, existentes no do grupo. Também diz respeito às regras formais existentes em estatutos e regimentos, bem como aos controles, monitoramentos e sanções formais e informais sobre os membros da rede;

- Sistemas de seleção de parceiros: regras e normas formais e informais para a seleção de parceiros. Este mecanismo se revelou de importância capital para o bom andamento das atividades da central de negócios estudada;

- Suporte público: Neste caso, foi feita uma adaptação deste conceito e, ao invés do suporte clássico dado por instituições do governo, colocou-se aqui a questão do papel da APAS - Associação Paulista de Supermercados na formação e manutenção da central de negócios estudada.

Conforme explicitado anteriormente, os mecanismos formais e informais de coordenação são importantes para se aferir a eficácia das organizações em redes de pequenos negócios supermercadistas. Especialmente quanto aos mecanismos informais, é importante considerá-los por meio da análise das relações existentes em rede.

A análise relacional fornece subsídios relevantes para que se possa conhecer a qualidade, intensidade e, portanto, coesão das relações existentes entre os membros de uma rede de cooperação. Relações coesas possibilitam o funcionamento adequado dos mecanismos informais de coordenação. Assim, dedicou-se o terceiro bloco de questões aos aspectos relacionais das redes para sua coesão. Novamente os subsídios teóricos que amparam as dimensões escolhidas para este nível de análise foram adaptados das contribuições de Sacomano Neto e Truzzi (2005) e Menard (2004), tal como segue:

- Vínculos anteriores: os laços prévios como fonte de informação confiável;

- Frequência da interação: volume de contatos, frequentes ou esporádicos. Uma frequência diária para semanal é considerada alta. Levou-se aqui também em consideração tempo de duração do contato, que se refere à qualidade das relações;

- Intensidade emocional: função da frequência das interações (maior frequência, maior intensidade emocional), mas também dimensionada pelas relações de amizade, participação em eventos, contatos, confiança e reciprocidade;

- Reciprocidade: foi dado um destaque especial a este quesito, tendo em vista as características da rede estudada. A reciprocidade aumenta a intensidade das relações e a qualidade da interação;

- Velocidade: rapidez na resolução de problemas ou difusão de informações.

Foi elaborado um roteiro original de entrevistas composto de 40 questões, duas delas abertas, voltadas para os depoimentos a respeito da trajetória do supermercadista entrevistado dentro e fora da rede e suas motivações para ingresso nela. Destas questões, para efeito deste artigo, 17, do total, são colocadas em destaque. Para facilitar as entrevistas, foram definidas alternativas e respostas quanto à satisfação com uma determinada situação ou concordância diante de uma proposição, contudo todas as alternativas foram traduzidas em termos de força. Os níveis de força considerados são cinco: muito forte, forte, força moderada, fraco e muito fraco, em ordem crescente de força. Desta forma, o número um é associado ao nível muito fraco de força, o número dois ao nível fraco e assim sucessivamente. A seguir, foi calculado o percentual que cada nível de força recebeu por parte dos seis entrevistados antes e depois da fusão com a rede maior, para se proceder então à análise geral.

\section{Análise de dados}

Neste item, são apresentados os quadros resumo e as respectivas análises para cada variável, em termos de percepção de eficácia, mecanismos de coordenação e atributo de coesão relacional. Considerando a mudança sofrida pela rede estudada, e que doravante passa a ser denominada rede Orion, e as significativas diferenças de percepção encontradas com relação a estes dois momentos, optou-se por 
colocar os percentuais de concordância do grupo com as afirmações propostas para cada nível de força referente aos dois momentos - antes da fusão (A.F.), na linha superior, e depois da fusão (D.F.), na linha inferior de cada tabela. No item seguinte, são feitas análises relacionadas aos resultados obtidos.

\subsection{Percepção de eficácia}

Como já mencionado, e de acordo com Behncker Jerônimo, Fensterseifer e Nunes da Silva (2005), é importante considerar a eficácia de maneira mais ampla. Assim, ao invés de aspectos quantitativos, como a evolução do faturamento e/ou lucro, foi dada ênfase especial aos aspectos não quantitativos, neste caso a percepção da evolução da competitividade e de atendimento ás expecativas de modo geral, o que pode implicar em faturamento/lucro, mas também inclui participação de mercado, por exemplo, como se vê na Tabela 3 , com relação à percepção de melhora de competitividade e atendimento de expectativas, percebe-se uma nítida diferença entre antes e depois da fusão com a rede $X$. De uma percepção de competitividade predominantemente moderada, existente quando saíram da operação individual para a cooperação na rede Orion passa-se a uma percepção muito forte de aumento de competitividade a partir da união de forças com a rede $\mathrm{X}$. Evolução semelhante se dá com as expectativas. O aumento da percepção de competitividade e das expectativas antes e, de maneira ainda mais acentuada, depois da fusão, se encontra em linha com as proposições já mencionadas de Soares et al. (2011), que apontam para benefícios competitivos resultantes da união sob a forma de redes., Especificamente com relação á fusão com a rede $\mathrm{X}$, a rede Orion, de porte menor e, portanto, com menores condições de obtenção de negociações vantajosas com fornecedores e dificuldade em acessar diretamente a indústria (menor competitividade), beneficia-se consideravelmente quando consegue fazer parte de um grupo mais estruturado e que possui maior poder de barganha e organização. Segundo relatos dos entrevistados, a resposta favorável dos clientes foi significativa, quando a rede Orion passou a fazer parte da rede $\mathrm{X}$ e oferecer melhores condições em termos de diversidade de produtos e preço.

De modo geral, a percepção de eficácia, entendida como o ajustamento entre expectativa e resultado
(BEHNCKER JERÔNIMO; FENSTERSEIFER; NUNES DA SILVA, 2005), fica aqui demonstrada, além da melhoria das percepções de aumento de competitividade e atendimento de expectativas, a partir do ingresso do supermercadista em uma rede, seja ela a rede Orion ou, mais ainda, na rede $\mathrm{X}$, tal como preconiza Soares et al. (2011). Por fim, como coloca Powell (1990), a ação em rede tem um papel importante na competitividade das empresas.

\subsection{Mecanismos de coordenação}

Neste quesito, as afirmativas buscaram aferir a percepção de força dos entrevistados a cerca dos mecanismos de coordenação de modo geral. Esta percepção, devido a já mencionada mudança pela qual passaram os integrantes da antiga rede Orion, foi dividida em dois momentos. Foram definidos alguns mecanismos que se relacionam mais diretamente com as atividades típicas de uma rede de cooperação de pequenos supermercadistas. Os mecanismos de coordenação escolhidos para este artigo foram extraídos das contribuições teóricas utilizadas neste trabalho, como a seleção de parceiros e suporte institucional (aqui personificado pela atuação da APAS), apresentados em Menard (2004), ou ainda os mecanismos de coordenação associados ao controle social (por normas informais, regras formais, sanções e monitoramento), existentes em Grandori e Soda (1995) e organizados segundo a apresentação existente em Sacomano Neto e Truzzi (2005). Apesar de menos pronunciados do que nos itens anteriores, também se observa um aumento geral de percepção de adequação e força, com relação aos mecanismos de coordenação, quando se passa da rede Orion para a rede $X$.

Um dos mecanismos que merece maior destaque é aquele relacionado à seleção de parceiros, contemplada na afirmação 7, das afirmações propostas. Este mecanismo, definido por Grandori e Soda (1995) como as regras informais e formais existentes na rede utilizadas para selecionar novos membros da mesma é considerado um dos mais importantes por Menard (2004) para a manutenção das formas híbridas. Na rede estudada, a forma de funcionamento deste mecanismo evidenciou a combinação entre o informal e formal na coordenaç̧ão da rede, sendo que, após a fusão, ele tem percepção de sua força intensificada. No processo

Tabela 3. Percepção de eficácia.

\begin{tabular}{|c|c|c|c|c|c|}
\hline Competitividade e expectativas & 1 & 2 & 3 & 4 & 5 \\
\hline 1 - aumento de competitividade (AF) & & $17 \%$ & $67 \%$ & $17 \%$ & \\
\hline 1 - aumento de competitividade (DF) & & & $17 \%$ & & $83 \%$ \\
\hline 2 - expectativas atingidas (AF) & & $33 \%$ & $33 \%$ & $17 \%$ & $17 \%$ \\
\hline 2 - expectativas atingidas (DF) & & & $17 \%$ & $17 \%$ & $67 \%$ \\
\hline
\end{tabular}


de escolha de novos integrantes, a rede estudada consulta os fornecedores de um possível parceiro sobre sua idoneidade e competência e, isto se dá de modo informal (conversas, consultas a fornecedores, etc.), por outro lado, existe também um procedimento previsto no estatuto da rede (aspecto formal). Em termos dinâmicos, como se vê na Tabela 4, antes da fusão $67 \%$ dos entrevistados manifestaram forte concordância (níveis 4 e 5) com a adequação dos procedimentos de seleção de parceiros. Após a fusão este indicador move-se para $100 \%$ de concordância. Novamente coerente com as proposições de Menard (2004), a importância do mecanismo de seleção de parceiros evidenciada no grupo estudado, demonstra que as estruturas híbridas são sistemas seletivos e não sistemas abertos. Seja para complementar recursos, seja para unir recursos (o que é o caso da rede Orion), a seleção de parceiros é fator-chave.

Outro mecanismo que se destacou neste estudo foi o de suporte institucional, representado pela atuação da APAS e sua importância no processo inicial de criação da rede Orion. Como mostra a Tabela 5. Este mecanismo, apresentado em Grandori e Soda (1995), destacado por Sacomano Neto e Truzzi, (2005), é definido como o apóio de entidades publicas para a manutenção da rede, e, nocaso deste trabalho, como já foi destacado no item 5 , foi considerada a atuação da APAS. Explorado na afirmação 8, o apoio institucional foi relevante na percepção dos supermercadistas entrevistados, como revelam os $83 \%$ para os níveis 4 e 5 de concordância com a afirmação que consta nesta questão. Nos relatos colhidos, ficou evidente que o papel da APAS não se resumiu apenas em ter fornecido os modelos de estatuto e regulamentos aos fundadores da rede Orion, mas também ao suporte realizado por meio de informações dadas pelo Comitê de Centrais de Negócio, existente na entidade desde 2000, bem como pelo apoio dado por este comitê aos participantes nas feiras e eventos promovidos pela APAS. Na verdade, Grandori e Soda (1995), quando se referem a este tipo de suporte externo para a consolidação das redes, eles se referem mais ao papel de agências e órgãos públicos nesta consolidação. Ocorre que, ao se fazer este estudo, a presença e a relevância da APAS ficaram tão evidentes que, em termos de infraestrutura e a despeito de ser uma entidade privada, foi considerada dentro desta classificação, adaptando-se para o caso em tela a utilização do termo "suporte institucional" ao invés de "suporte público e infraestrutura", tal como é encontrado originariamente nos trabalhos destes autores.

Em linha com as proposições de Menard (2004), as complementaridades geradas em redes híbridas podem trazer consigo especificidades de ativo geradoras de comportamentos oportunistas ou ainda atitudes de "caronas", geradores de custos de transação. Os mecanismos para enfrentar os problemas advindos desta situação, segundo Menard (2004), são sanções contratualmente explicitadas, esquemas de monitoramento e processos criteriosos de seleção de parceiros. A exemplo das formulações de Menard (2004) sobre formas híbridas de governança e de Grandori e Soda (1995) sobre mecanismos de coordenação de redes, a seleção de novos parceiros e o suporte/infraestrutura (neste caso representado pelo apoio institucional dado pela APAS) se constituem em mecanismos de coordenação importantes para as redes de cooperação sob a forma de centrais de negócios supermercadistas. Prosseguindo na análise, passa-se para mecanismos formais e informais de coordenação ligados a controle social e monitoramento. De acordo com Grandori e Soda (1995), os arranjos interorganizacionais sob a forma de redes cooperativas possuem uma faceta social que não pode ser desprezada. Por isso foram escolhidos alguns indicadores relacionados com controle social e monitoramento, definidos como mecanismos informais e analisados através da percepção dos integrantes quanto à força das normas de comportamento socialmente aceitas e esperadas dentro de um grupo cooperativo, tais como atitudes éticas e cooperativas, e quanto à efetividade sanções contra comportamentos não desejados nestes mesmos termos. Também, novamente de acordo com Grandori e Soda (1995) e Sacomano Neto e Truzzi, (2005), foram considerados mecanismos de coordenação eminentemente formais, tais como regras dispostas em contratos e estatutos e esquemas de monitoramento de integrantes da rede formalmente definidos, em termos de adequação destes integrantes quanto ao comportamento em pró da coordenação. Como exemplo deste último quesito,

Tabela 4. Coordenação.

\begin{tabular}{|c|c|c|c|c|c|}
\hline Seleção de parceiros & 1 & 2 & 3 & 4 & 5 \\
\hline 7 - Seleção de parceiros - A.F. & & $17 \%$ & $17 \%$ & $17 \%$ & $50 \%$ \\
\hline 7 - Seleção de parceiros - D.F. & & & & $33 \%$ & $67 \%$ \\
\hline
\end{tabular}

Tabela 5. Coordenação.

\begin{tabular}{|c|c|c|c|c|c|}
\hline Suporte público e infraestrutura & 1 & 2 & 3 & 4 & 5 \\
\hline 8 - Apoio institucional & & & $17 \%$ & $33 \%$ & $50 \%$ \\
\hline
\end{tabular}


tem-se a instituição do chamado "fiscal da rede", uma atribuição rotativa dentro do grupo na qual o fiscal do momento percorre os estabelecimentos dos integrantes da rede e verifica a observância das regras previamente estabelecidas, tais como a presença de produtos de fornecedores definidos pela rede e ausência daqueles que não possuem acordo com ela. Conforme se vê na Tabela 6, com atribuição menor de força, tem-se os mecanismos de coordenação relacionados ao controle e monitoramento dos participantes da rede estudada. Registra-se um aumento da importância dada pelos supermercadistas, após a fusão, dos aspectos informais destes mecanismos. Por exemplo, para a disposição normativa de comportamento em termos éticos e cooperativos, um mecanismo normativo informal que delimita comportamentos (afirmação 3), a maioria dos supermercadistas escolheram os níveis de concordância 4 e 5 (forte e muito forte) após a fusão, enquanto que apenas $17 \%$ havia optado por estes níveis antes dela. Este crescimento da percepção da importância das normas informais de comportamento após a fusão se revela um dado interessante, pois, ao participar de uma organização mais estruturada e, portanto, mais burocratizada, seria de se esperar o contrário, ou seja, uma maior importância a formalização.

Contudo, também foi dado um nível de força considerável para as regras do estatuto (um mecanismo formal, contemplado na afirmação 4), demonstrando uma convivência entre mecanismos formais e informais, convivência esta também constatada a partir dos relatos gravados e colhidos junto aos supermercadistas da rede Orion.

Apesar de também apresentar um aumento entre antes e depois da fusão, menor valor de força foi dado para as sanções previstas e também para a fiscalização mais direta sobre os membros. Em que pese a relevância dos mecanismos formais e a convivência entre estes e os mecanismos informais e de acordo com os percentuais registrados na
Tabela 6, o comportamento normativo demonstra ser o mecanismo que se sobressai. Além disso, dentro de uma perspectiva dinâmica, percebe-se que a coordenação de modo geral se reforça, mantendo-se a relevância do aspecto normativo na percepção dos integrantes da rede Orion na nova condição de partícipes de uma rede maior.

Tanto antes como depois da fusão, o que se observa neste item sobre os mecanismos de coordenação, dentro da perspectiva de Grandori e Soda (1995) e Sacomano Neto e Truzzi, (2005), acima analisados, é que, em primeiro lugar, ressalta-se a idéia da necessidade de coordenação para manutenção da rede. Esta coordenação é importante para anular ou, pelo menos, minimizar a ação do aportunismo em arranjos híbridos do tipo rede interorganizacional, tal como colocado em Menard (2004). Também segundo este mesmo autor, a coordenação é importante para se fazer frente a questão da oposição entre interdependencia e autonomia existente em arranjos híbridos analisados por Menard (2004). Por outro lado, a convivência entre mecanismos formais e informais, com a relativa predominância dos ultimos sobre os primeiros, reafirma a possibilidade de, utilizando ainda a tipologia de Menard (2004), classificar a rede estudada como um arranjo híbrido do tipo associação/ cooperação, no qual a confiança (fator informal), tem papel importante para o bom funcionamento das transações deste tipo de arranjo.

\subsection{Coesão relacional}

Neste item, são trabalhados os aspectos relacionais da análise de redes. Entre estes, os atributos que mereceram maior destaque são analisados a seguir.

$\mathrm{Na}$ afirmação 9, os relacionamentos prévios, tal como se vê na Tabela 7, foram considerados pelos integrantes da rede como de força moderada a forte (67\% para os níveis 4 e 5 e $33 \%$ para o nível 2).

Tabela 6. Coordenação.

\begin{tabular}{|c|c|c|c|c|c|}
\hline Controle s/ parceiros & 1 & 2 & 3 & 4 & 5 \\
\hline 3 - Importância de normas de comportamento - A.F. & & & $83 \%$ & $17 \%$ & \\
\hline 3 - Importância de normas de comportamento - D.F. & & & $17 \%$ & $50 \%$ & $33 \%$ \\
\hline 4 - Importância de regras formais - A.F. & $17 \%$ & & $83 \%$ & & \\
\hline 4 - Importância de regras formais - D.F. & & & $17 \%$ & $33 \%$ & $50 \%$ \\
\hline 5 - Importância da percepção de sanções - A.F & $50 \%$ & $17 \%$ & $17 \%$ & $17 \%$ & $17 \%$ \\
\hline 5 - Importância da percepção de sanções - D.F & & & $33 \%$ & $\mathbf{5 0 \%}$ & $17 \%$ \\
\hline 6 - Importância de monitoramento - A.F. & $20 \%$ & & $20 \%$ & $20 \%$ & $20 \%$ \\
\hline 6 - Importância de monitoramento - D.F. & $20 \%$ & & $40 \%$ & & $40 \%$ \\
\hline
\end{tabular}

Tabela 7. Coesão relacional.

\begin{tabular}{lccccc}
\hline & Vínculos prévios & 1 & 2 & 3 & 4 \\
\hline $9-$ Vínculos prévios & & $33 \%$ & & $\mathbf{1 7 \%}$ & $\mathbf{5 0 \%}$ \\
\hline
\end{tabular}


Neste caso, a exemplo da afirmação relacionada à APAS, não se considerou o efeito dinâmico, pois o que se buscou aferir foram os vínculos prévios antes da entrada na rede Orion.

Os relacionamentos ou vínculos prévios, tal como é apontado em Sacomano Neto e Truzzi (2005), são um fator de coesão relacional importante, pois o conhecimento mútuo se constitui em uma fonte de informação confiável entre os participantes de um arranjo cooperativo. No entanto não é um mecanismo que não apresentou, no computo geral, a mesma percepção de força para os integrantes da Orion do que outros mecanismos, como se verá a seguir.

A frequência das interações entre os membros da rede é outro mecanismo de coesão relacional entre os apontados em Sacomano Neto e Truzzi (2005) e escolhido como variável de análise para o conjunto de afirmações que amparou este trabalho. Quanto maior o volume de contatos entre os integrantes de uma rede (de semanal para diário, por exemplo), maior a intensidade das relações e maior, portanto, a coesão relacional. Por outro lado, o tempo de duração dos encontros também é considerado, pois acrescenta um aspecto de qualidade ao contato. Quanto à frequência das relações (afirmações 10 a 12), de modo geral, se revela um grau de forte frequência, antes e depois da integração. Em média, também não se observam variações expressivas de força, antes e depois da integração, tanto em termos da frequência de contatos informais, como em encontros mais estruturados, representados pelas reuniões semanais. Em ambas as situações, como se observa na Tabela 8, as relações são caracterizadas por forte frequência. Já quanto à qualidade percebida desta relação, especialmente com relação às reuniões, apesar de forte, o nível é inferior aos demais, indicando espaço para melhorias.
Grandori e Soda (1995), em seu trabalho sobre redes, dão um destaque especial para a confiança. Em seu entendimento, a confiança é um dos mais importantes conceitos relacionados a redes interorganizacionais. Para estes autores, na presença da confiança, os membros de uma rede agirão em benefício do sistema de cooperação ao qual pertencem, pois sentem convergência entre seus interesses e os do sistema. A presença da confiança contribui positivamente para a intensidade emocional, outro atributo para a coesão relacional indicado em Sacomano Neto e Truzzi (2005), sendo que se desenvolve de maneira informal. No caso da rede estudada, evidencia-se grande força na importância da confiança para a manutenção da cooperação, tanto antes como depois da fusão (100\% de escolhas para os níveis 4 e 5 antes e depois da fusão) e, por outro lado menor força para a necessidade de monitoramento (após a fusão, apenas $33 \%$ consideram importante algum tipo de monitoramento), que seria justamente um mecanismo a ser empregado quando a intensidade da confiança é baixa. Essa situação indica a relevância das relações baseadas mais na confiança e, portanto, na informalidade. Esta relevância da informalidade ressalta a importância da coordenação por normas de comportamento, objeto de análise do item anterior, que tem como pressuposto básico a realização da coordenação de forma informal, sem regras escritas.

Na Tabela 9 a seguir, tem-se os quesitos relacionados com a intensidade emocional (questões 13 e 14), destacados para este estudo, e seus respectivos percentuais de concordância:

A reciprocidade é outro atributo relacional definido em Sacomano Neto e Truzzi (2005) e que indica coesão nas relações. Quanto maior a reciprocidade entre os integrantes de uma rede cooperativa, mais fortes vão se tornando as relações e, consequentemente, a coesão

Tabela 8. Coesão relacional-frequência.

\begin{tabular}{lccccc}
\hline \multicolumn{1}{c}{ Frequência } & $\mathbf{1}$ & $\mathbf{2}$ & $\mathbf{3}$ & $\mathbf{4}$ & $\mathbf{5}$ \\
\hline 10 - Suficiência da frequência na troca de informações - A.F. & $17 \%$ & & $33 \%$ & $33 \%$ & $17 \%$ \\
$\mathbf{1 0}$ - Suficiência da frequência na troca de informações - D.F. & & & $\mathbf{1 7 \%}$ & $\mathbf{1 7 \%}$ & $\mathbf{6 7 \%}$ \\
11 - Suficiência da frequência dos encontros - A.F & & & $17 \%$ & $50 \%$ & $33 \%$ \\
$\mathbf{1 1}$ - Suficiência da frequência dos encontros - D.F & & $\mathbf{1 7 \%}$ & & $\mathbf{6 7 \%}$ & $\mathbf{1 7 \%}$ \\
12 - Suficiência na duração dos encontros - A.F. & & & $17 \%$ & $83 \%$ & \\
$\mathbf{1 2}$ - Suficiência na duração dos encontros - D.F. & $\mathbf{1 7 \%}$ & $\mathbf{1 7 \%}$ & $\mathbf{6 7 \%}$ \\
\hline
\end{tabular}

Tabela 9. Coesão relacional.

\begin{tabular}{|c|c|c|c|c|c|}
\hline Intensidade emocional & 1 & 2 & 3 & 4 & 5 \\
\hline 13 - importância da confiança - A.F. & & & & $50 \%$ & $50 \%$ \\
\hline 13 - importância da confiança - D.F. & & & & $\mathbf{5 0 \%}$ & $\mathbf{5 0 \%}$ \\
\hline 14 - Necessidade de Monitoramento - A. F. & & & $33 \%$ & $50 \%$ & $17 \%$ \\
\hline 14 - Necessidade de Monitoramento - D. F. & $17 \%$ & & $50 \%$ & & $33 \%$ \\
\hline
\end{tabular}


relacional da rede aumenta. Este atributo mereceu destaque neste artigo devido à relação que possui com a confiança e com os mecanismos informais de coordenação. Está presente de maneira explícita na rede estudada pelo esquema de compensação de excessos e faltas de mercadorias que foi relatado por alguns entrevistados. Um integrante, por exemplo, que esteja com falta de mercadoria, ao invés de adquiri-la no fornecedor ou em outro estabelecimento, pagando mais caro, pode emprestar esta mercadoria de quem a tenha sobrando, devolvendo-a numa próxima oportunidade, ou pagando o valor equivalente em dinheiro. Da mesma forma, caso alguma mercadoria esteja sem saída, esta pode ser encaminhada para outro estabelecimento, no qual sua demanda esteja mais forte. É realizada de maneira totalmente informal e baseada na confiança entre as partes envolvidas nesta transação. É importante ressaltar que este tipo de prática, apesar de previsto no estatuto da rede, se dá no dia a dia de maneira não formalizada, sem nenhum tipo de papel ou registro (a não ser os controles internos de entradas e saídas de mercadorias, feitos pelo supermercadista no âmbito de sua loja), totalmente realizado em termos de confiança, sem nenhum contrato que preveja sanções àqueles que não cumpram com a sua parte neste acordo: "não tem recibo, não tem nada, é na base da confiança mesmo" (supermercadista entrevistado).

Conforme se observa na Tabela 10 (afirmação 15), a reciprocidade apresenta grande força $(100 \%$ das escolhas apontando satisfação 4 e 5 para este mecanismo). A exemplo de Powell (1990) que também dá grande importância a este aspecto, a reciprocidade é característica marcante das relações na rede estudada.

A importância do caráter informal baseado em confiança é ressaltada por todos os entrevistados, eles não veem a necessidade de, por exemplo, redigir um contrato que preveja os direitos e obrigações quando um supermercadista recebe de outro uma quantidade de mercadoria que será posteriormente devolvida; isso complica o processo (gera custos de transação). Não há dúvida, entre eles, de que haverá a compensação. Por outro lado, eles mesmos reconhecem falhas de controles internos. Apenas alguns mantêm registros de entrada e saída das mercadorias relacionadas ao esquema de compensação e, portanto, vez ou outra, ocorrem esquecimentos. Mas, imediatamente, quando lembrados pelo parceiro da transação, ocorre o ressarcimento. Assim, não há dúvidas quanto ao comportamento em termos de honestidade. A confiança e a reciprocidade aqui se manifestam de maneira marcante e possibilitam o funcionamento de uma transação com mais baixos custos, embora se reconheça a necessidade de aprimoramento nos controles para maior eficiência do processo.

Recorrendo agora a Powell (1990), encontram-se diversas correspondências entre suas formulações e este caso. Numa perspectiva mais geral, os pequenos estabelecimentos supermercadistas estabelecem relacionamentos geradores de externalidades positivas e de condições competitivas, capazes de enfrentar a pressão de um mercado crescentemente concentrado como o varejo supermercadista, garantindo a sua sobrevivência em face desta pressão.

A reciprocidade, tema também trabalhado por Powell (1990), e suas dimensões basicamente polarizadas entre uma dimensão autointeressada, calculista e outra sociológica calcada em aspectos normativos, especialmente em termos do compromisso para a cooperação e na importância da retribuição, encontra exemplo marcante no já mencionado sistema de troca de mercadorias, no qual é possível perceber estes dois lados, cálculo e cooperação, convivendo em normalidade.

Por fim, Sacomano Neto e Truzzi (2005) entendem que a velocidade em termos de disseminação de informações e resolução de problemas, contemplada nas afirmações 16 e 17 do roteiro (v. Tabela 11), é também um atributo importante para a aferição da coesão relacional. Quanto mais rapidamente as informações fluem dentro do grupo e os problemas e obstáculos são vencidos, as relações se tornam cada vez mais intensas, aumentando, portanto, a coesão

Tabela 10. Coesão relacional - reciprocidade.

\begin{tabular}{|c|c|c|c|c|c|}
\hline Reciprocidade & 1 & 2 & 3 & 4 & 5 \\
\hline 15 - Existência de reciprocidade - A.F. & & & & $17 \%$ & $83 \%$ \\
\hline 15 - Existência de reciprocidade - D.F. & & & & $17 \%$ & $83 \%$ \\
\hline
\end{tabular}

Tabela 11. Coesão relacional.

\begin{tabular}{|c|c|c|c|c|c|}
\hline Velocidade & 1 & 2 & 3 & 4 & 5 \\
\hline 16 - Na disseminação de informações - A.F. & & $17 \%$ & $67 \%$ & $17 \%$ & \\
\hline 16 - Na disseminação de informações - D.F. & & & & $50 \%$ & $\mathbf{5 0 \%}$ \\
\hline 17 - Na resolução de problemas - A.F. & & $17 \%$ & $83 \%$ & & \\
\hline 17 - Na resolução de problemas - D.F. & & & $17 \%$ & $83 \%$ & \\
\hline
\end{tabular}


relacional do grupo. Conforme se vê a seguir, este item recebe forte atribuição de força, com evolução considerável após a fusão, especialmente no caso da velocidade de disseminação de informações.

A relevância observada na rede Orion dos aspectos informais da coordenação, chama novamente a atenção para a contribuição de Powell (1990) e sua visão da natureza social da coordenação da atividade econômica e de sua dependência de fatores socialmente enraizados, tais como relacionamentos, reputação, confiança.

A partir da análise da percepção de força das variáveis de coesão relacional utilizadas neste trabalho, se nota que as relações existentes na rede analisada podem ser caracterizadas como coesas do ponto de vista relacional, pois possuem graus de força de forte para muito forte em média, para a maioria dos atributos, apontando para relações recíprocas, frequentes, confiantes e informais. Estes níveis aumentam a partir da fusão, revelando um impacto relevante e positivo para os integrantes da antiga rede Orion.

\section{Considerações finais}

Este trabalho foi direcionado para a percepção de eficácia, a contribuição dos mecanismos formais e informais de coordenação e das características das relações em termos de coesão relacional, especialmente sua contribuição para a coordenação informal. Neste caso, também se levou em conta a dinâmica experimentada pelos supermercadistas da rede Orion. Os elementos para as conclusões foram construídos com informações colhidas em relatos junto aos supermercadistas.

A percepção de eficácia do grupo, na forma como foi tratada neste artigo, em termos não financeiros (aumento de competitividade e atendimento geral de expectativas), se revela positiva e forte e com maior intensidade quando ocorre a fusão. Dessa condição, emergem duas conclusões. A primeira é que o arranjo cooperativo em rede para os pequenos supermercadistas tem sido exitoso na sua percepção e, portanto, constitui uma alternativa relevante para a sobrevivência dos pequenos negócios supermercadistas em mercado crescentemente concentrado em um número reduzido de grandes grupos. Em segundo lugar, o porte da rede também tem relevância. Quando se unem a uma rede maior, com maior número de integrantes e, consequentemente, maior poder de mercado (especialmente junto aos fornecedores), a percepção de eficácia, que já era grande, com a passagem de uma atuação individual dos pequenos supermercadistas da rede Orion para uma atuação cooperativa, aumenta mais ainda quando se juntam à rede maior. Isso revela que a escala neste tipo de rede, e diferentemente de outras redes tais como as redes de cunho mais tecnológico, é um fator competitivo a ser considerado.

A fonte do aumento da percepção de eficácia, conforme as proposições iniciais deste trabalho, emerge da forma como ela se coordena (mecanismos de coordenação) e da intensidade das relações entre seus membros (coesão relacional). No caso dos mecanismos de coordenação, de modo geral, estes, percebidos como fortes pelo grupo estudado antes da fusão, apresentam um aumento na percepção desta força quando ocorre a fusão. Entre os mecanismos analisados, registrou-se uma relevância especial nos relatos colhidos junto aos supermercadistas entrevistados para a seleção de parceiros, apoio institucional, de acordo com a literatura utilizada neste trabalho (MENARD 2004; GRANDORI; SODA, 1995). Além disso, notou-se a falta de predominância entre os mecanismos mais formais do tipo enforcement (regras formais, percepção de sanções e monitoramento), preconizados na vertente econômica do institucionalismo e os de dimensão mais informal, de cunho social (vínculos prévios, normas e expectativas de comportamentos), revelando-se uma convivência entre o formal (econômico) e o informal (sociológico).

Também os mecanismos específicos de formas híbridas sob a forma de redes interorganizacionais - a saber, seleção de parceiros e apoio institucional - se apresentaram na rede estudada com aspectos formais e informais. Ainda com relação aos mecanismos de coordenação, o que se encontrou nos relatos colhidos por ocasião da pesquisa de campo junto à rede Orion, foi a existência destes mecanismos com aspectos formalizados ao lado de aspectos informais complementares e de grande relevância, como segue:

- Sanção: o estatuto e regulamento da rede. O conhecimento não era o ideal, assim as regras funcionavam por um esquema mais normativo, construído na própria interação cotidiana dos membros, conversas entre dois ou mais membros, reuniões formais e sociais, etc;

- Esquemas de monitoramento: o fiscal da rede. Relata-se que este procedimento, em que pese ter sido considerado importante, não funcionou de maneira satisfatória e, de novo, as conversas e reuniões, como mecanismos informais, têm aqui papel relevante;

- Seleção de parceiros: levantamento sobre a reputação junto a fornecedores e/ou convite a supermercadistas já conhecidos no mercado pelo sucesso empresarial, na visão dos entrevistados. Este esquema possui uma funcionalidade satisfatória, mas também existem casos em que alguns membros foram convidados devido ao conhecimento prévio ou experiência passada entre estes e algum componente da rede. 
Em todos os itens anteriores, a combinação da formalidade e da informalidade é evidente e relevante para se entender o desenvolvimento da central de negócios analisada. É esta combinação que incrementa a eficácia da rede. Ocorre que a força da coordenação para a eficácia da rede, especialmente na parcela informal, se concretiza a partir da existência de uma coesão relacional forte. Em outras palavras, enquanto o aspecto formal da coordenação é garantido a princípio pela própria formalidade dos processos (por exemplo, o estatuto da rede), a dimensão informal carece da existência de um alto índice de coesão nas relações. Sem relações coesas não há muito espaço, por exemplo, para a existência da confiança, ingrediente fundamental da informalidade.

Sobre os atributos relacionais para a coesão apontados em Sacomano Neto e Truzzi (2005) e Powell (1990), utilizados neste trabalho (vínculos prévios, frequência, velocidade, intensidade emocional, reciprocidade), tem-se que, todos eles, mas especialmente a reciprocidade e a intensidade nas relações no que tange à confiança, apresentaram-se com evolução semelhante ao ocorrido com os mecanismos de coordenação, ou seja, índices fortes, tanto antes como depois da fusão e com o aumento da intensidade de alguns após esta, o que corrobora a existência da relação positiva entre a força da coordenação, especialmente em seu aspecto informal, e a coesão relacional. Em outras palavras, a coesão forte gera a possibilidade da informalidade na coordenação (mesmo que compartilhada com mecanismos formais), o que, por sua vez, e nesta conformação, proporciona maior percepção de eficácia.

Em linha com as proposições iniciais deste trabalho, as redes ou centrais de compra podem ser consideradas como uma alternativa de governança baseada em uma mescla de mecanismos formais e informais em que existem reciprocidade e confiança ao lado de monitoramento e controle, interesse mútuo e relacionamentos sociais ao lado de interesse estratégico e transações econômicas, com interdependência sem perda de autonomia. As atividades se desenvolvem dentro de uma concepção mensurável que vem a ser o ganho econômico no custo de aquisição a partir da compra conjunta, mas também existem outros ganhos não mensuráveis, e reconhecidamente importantes, definidos pela troca de experiências e informações, por exemplo.

Assim, a percepção de eficácia do grupo se revela positiva, forte e crescente a partir da integração com a rede maior, com destaque especial para a seleção de parceiros e para a convivência entre o formal e informal no processo de coordenação. Constata-se a coesão existente na central analisada, sendo que os elementos de rede com maior potencial são: a frequência, a velocidade, a intensidade emocional e, especialmente, a confiança e a reciprocidade.

\section{Referências}

ASSOCIAÇÃO BRASILEIRA DE SUPERMERCADOS - ABRAS. Comitê de Centrais de Negócios. Quadro: Lojas Associadas às Centrais de Negócios. São Paulo: ABRAS, 2010a.

ASSOCIAÇÃO BRASILEIRA DE SUPERMERCADOS ABRAS. Ranking ABRAS. ABRAS, 2010b. Disponível em: <http://www.abrasnet.com.br/economia-e-pesquisa/ ranking-abras/>. Acesso em: nov. 2010.

BEHNCKER JERÔNIMO, F.; FENSTERSEIFER, E.; NUNES DA SILVA, T. Instituições, eficiência, gestão e contratos no sistema agroindustrial. In: CONGRESSO SOBER, 43., 2005, Porto Alegre. Anais... Porto Alegre: UFRGS, 2005.

ESTEVES, C. Indústria aperta o varejo. Jornal Gazeta Mercantil, abr. 2009. Resenha Eletrônica. Disponível em <http://www.fazenda.gov.br/resenhaeletronica/ MostraMateria.. sp? $\operatorname{cod}=543158>$. Acesso em: 07 set. 2009.

GRANDORI, A.; SODA, G. Inter-firm Networks: Antecedents, Mechanisms and Forms. Organization Studies, v. 16, n. 2, p. 183-214, 1995. http://dx.doi. org/10.1177/017084069501600201

HILÁRIO, W. Ranking 2008 - Setor recobra fôlego e cresce acima do PIB. Revista Super Hiper, p. 36-118, abr. 2008 .

HOLMLUND, M.; TORNROSS, J. A. What are relationships in business networks? Managemant Decision, v. 35, n. 4, p. 304-309, 1997. Disponível em: <http:// www.emeraldinsight.com/journals.htm?issn $=0025$ $1747 \&$ volume $=35 \&$ issue $=4>$. Acesso em 12 fev. 2010 .

LUKIANOCENKO, M. Ranking 2007 - Ano estável para o setor supermercadista. Revista Super Hiper, p. 34-114, maio 2007.

MADUREIRA, D. N. Apostar em nichos é opção para as redes menores: supermercados com vendas abaixo de R\$ 1 bi avaliam caminhos. Jornal Valor Econômico, São Paulo, p. B4, 11 mar. 2007.

MARTINELLI, D. P.; GHISI, A. F.; CAMARGO, S. H. R. $\mathrm{V}$. Redes de compras de supermercados de pequeno e médio porte: um estudo multicaso no interior do estado de São Paulo. In: ANGELO, C. F.; SILVEIRA, J. A. G. (Org.). Varejo Competitivo. São Paulo: Atlas, 2002. v. 7.

MENARD, C. The economics of hybrids organizations. Journal of institutional and theoretical economics, p. 345-376, 2004. http://dx.doi. org/10.1628/0932456041960605

MOLDERO, R. H. O pequeno varejo resiste às fusões. Revista Distribuição, p. 18-28, maio 1998.

NEVES, J. L. Pesquisa qualitativa: características, usos e possibilidades. Caderno de Pesquisas em Administração, v. 1, n. 3, p. 1-5, 1996.

POWELL, W. W. Neither market nor hierarchy: network forms of organization. Research in Organization Behavior, v. 12, p. 295-336, 1990.

POWELL, W. W.; SMITH-DOERR, L. Networks and economic life. The Handbook of Economic Sociology, v. 368, p. 380, 1994.

PROVAN, K. G.; FISH, A.; SYDOW, J. Interorganizational Networks at the Network Level: A Review of the Empirical Literature on Whole Networks. Journal of 
Management, v. 33, p. 479-516, 2007. Disponível em $<$ http://jom.sagepub.com>. Acesso em: 10 fev. 2010.

SAAB, W. G. L.; GIMENEZ, L. C. P. Supermercados no Brasil: o movimento das empresas menores. Rio de Janeiro: BNDES, 2000. (BNDES Informe Setorial, n. 24).

SACOMANO NETO, M.; TRUZZI, O. M. S. Governança e análise de redes. In: FUSCO, J. P. A. (Org.). Redes Produtivas e Cadeias de Fornecimento. São Paulo: Arte \& Ciência Editora, 2005.

SOARES, A. S. et al. Benefícios competitivos e conflitos em rede horizontal do setor supermercadista. Revista
Eletrônica de Administração, v. 17, n. 2, p. 530-559, maio/jun. 2011. Disponível em: <http://read.adm. ufrgs.br/edicoes/download.php?cod_artigo=702\&cod_ edicao $=70>$. Acesso em: 07 maio 2012.

WILDER, A. Mudanças no setor supermercadista e a formação de associações de pequenos supermercados. 2003. 208 f. Dissertação (Mestrado em Ciências Economia Aplicada)-Escola Superior de Agricultura Luiz de Queiroz, Universidade de São Paulo, Piracicaba, 2003.

YIN, R. K. Estudo de caso: planejamento e métodos. 2. ed. Porto Alegre: Bookmam, 2001.

\section{Anexo - Afirmações utilizadas}

Q. 1. A minha empresa aumentou sua competitividade com a participação na central.

Q. 2. Meus objetivos e expectativas iniciais, quando ingressei na rede, foram atendidos.

Q. 3. A disposição de comportamento dos supermercadistas enquanto associados da central em termos de conduta ética, participação, postura cooperativa, busca do bem comum, na sua visão, tem sido adequada.

Q. 4. Com relação às regras e condutas definidas no estatuto da central e seu funcionamento, estas regras são adequadas.

Q. 5. No caso das sanções que poderão ocorrer, a chance de alguém sofrê-las caso quebre as normas é grande.

Q. 6. Sobre a fiscalização ou monitoramento dos associados da central, a importância e a presença dos esquemas de monitoramento sobre a conduta dos associados são grandes.

Q. 7. As regras e procedimentos para a seleção de novos parceiros da central (análise de experiência passada, arranjos prévios, reputação, informações de terceiros e fornecedores) têm funcionado de maneira adequada.

Q. 8. A importância da APAS no processo de formação da central foi grande.

Q. 9 Já conhecia ou teve algum tipo de relacionamento com algum associado antes de ingressar na rede? Classifique este vinculo como muito forte (4), forte (3), fraco (2), muito fraco (1).

Q. 10. Com relação à frequência de troca de informações (diária, semanal, mensal), essa frequência é suficiente.

Q. 11. Com relação à periodicidade dos encontros (diária, semanal, mensal), esta periodicidade hoje é, para o sucesso da rede, suficiente.

Q. 12. Com relação ao tempo de duração dos encontros, este é suficiente.

Q.13. A importância da confiança entre os associados da rede é vital.

Q. 14. A necessidade de monitorar e controlar as ações dos associados para que haja segurança quanto ao seu desempenho é importante.

Q. 15 Em termos de reciprocidade (por exemplo: compensação mútua de mercadorias), poderia se dizer que ela ocorre de maneira relevante e forte.

Q. 16 Com relação à velocidade de disseminação de informações da rede, ela é adequada.

Q. 17 Quando surge um problema, o tempo/prazo no qual ele é comunicado e resolvido é adequado. 